\title{
Exchange Coupling and the Grain Boundary in Magnetic Nanocomposites
}

\author{
K. O'Donnell, X-L Rao, J. R. Cullen and J. M. D. Coey
}

Department of Physics, Trinity College, Dublin 2, Ireland.

\begin{abstract}
The grain boundary phase/material found to be present in two-phase mechanically alloyed nanocomposites of $\mathrm{Sm}_{2} \mathrm{Fe}_{17} \mathrm{~N}_{3} / \mathrm{Fe}$ and $\mathrm{Nd}_{2} \mathrm{Fe}_{14} \mathrm{~B} / \mathrm{Fe}$ was characterized using Mössbauer spectroscopy and magnetization measurements. The fraction of iron in this third component is typically $10-15 \%$ in $\mathrm{Sm}_{2} \mathrm{Fe}_{17} \mathrm{~N}_{3} / \mathrm{Fe}$ and $4-5 \%$ in $\mathrm{Nd}_{2} \mathrm{Fe}_{14} \mathrm{~B} / \mathrm{Fe}$ nanocomposites. The influence of the grain size of the nanocomposite and the grain boundary material on the susceptibility was studied and the results are discussed in terms of the model of Wang and Mills.
\end{abstract}

\section{INTRODUCTION}

Isotropic two-phase nanocomposite magnets composed of a hard and a soft magnetic phase which are exchange coupled may show 'single-phase' hysteresis behaviour with useful properties including high recoil permeability and a remanence which is much greater than that of the hard phase by itself. Typical systems are $\mathrm{Nd}_{2} \mathrm{Fe}_{14} \mathrm{~B} / \mathrm{Fe}$, $\mathrm{Nd}_{2} \mathrm{Fe}_{14} \mathrm{~B} / \mathrm{Fe}_{3} \mathrm{~B}$ and $\mathrm{Sm}_{2} \mathrm{Fe}_{17} \mathrm{~N}_{3} / \mathrm{Fe}$ which may be prepared by melt spinning or mechanical alloying [1]. High resolution electron microscopy has provided images of the two-phase nanostructure. Micromagnetic computer simulations are based on a random cellular structure where grains of the two phases may have different average sizes [2]. To preserve the coercivity in the random exchangecoupled nanocomposites, the size of the grains must be of the order of $10 \mathrm{~nm}$. Numerical micromagnetic calculations of two-phase nanocomposites where a third, grain boundary component of thickness $1 \mathrm{~nm}$ is included, have recently been carried out [3] where it has been shown that the magnetic properties of the model system strongly depend on the exchange constant of the interphase region.

Efficient exchange coupling depends critically on the interface. Here we present the first characterization of the grain boundary material in $\mathrm{Sm}_{2} \mathrm{Fe}_{17} \mathrm{~N}_{3} / \mathrm{Fe}$ and $\mathrm{Nd}_{2} \mathrm{Fe}_{14} \mathrm{~B} / \mathrm{Fe}$ nanocomposites; showing how the susceptibility in the vicinity of the Curie temperature differs for well-coupled and poorly-coupled samples. We then discuss the influence of intergranular exchange on the susceptibility anomalies near the Curie temperatures of the hard and soft phases.

\section{EXPERIMENTAL METHODS}

Two-phase nanocomposites of $\mathrm{Sm}_{2} \mathrm{Fe}_{17} \mathrm{~N}_{3} / \alpha-\mathrm{Fe}$ and $\mathrm{Nd}_{2} \mathrm{Fe}_{14} \mathrm{~B} / \alpha-\mathrm{Fe}$ were prepared by mechanical alloying of elemental powders and subsequent annealing (and

Manuscript received January 27, 1997

K. O'Donnell, Institut für Physikalische Hochtechnologie e. V., PF 100 239, D-07702, Jena, Germany. Tel:0049-3641-302 784 Fax:0049-3641302-799 Email Address:KODONNLL@main.ipht-jena.de nitrogenation in the case of $\mathrm{Sm}_{2} \mathrm{Fe}_{17} \mathrm{~N}_{3} / \alpha-\mathrm{Fe}$ ). Typical preparation conditions were mechanical alloying for 64 hours in a Fritsch high-energy planetary ball mill followed by a 10 minute anneal in vacuum at $625^{\circ} \mathrm{C}$ (and then nitrogenation in 1 bar of $\mathrm{N}_{2}$ gas at $330^{\circ} \mathrm{C}$ for 45 hours). The crystallization of the hard phase from the mainly amorphous precursor, formed during the mechanical alloying process is the primary factor determining the grain size in the resulting nanostructure. In the case of the $\mathrm{Sm}_{2} \mathrm{Fe}_{17} \mathrm{~N}_{3} / \alpha-\mathrm{Fe}$ nanocomposite, 2 at. $\% \mathrm{Zr}$ was included in the starting mixture to control the grain growth during crystallization. It is dissolved in the Fe during mechanical alloying as evidenced by a $0.4^{\circ}(2 \theta)$ shift of the (110) X-ray diffraction peak of the $\alpha-F e$ towards a lower diffraction angle. During crystallization of the $\mathrm{Sm}_{2} \mathrm{Fe}_{17}$ phase the additive appears to be rejected to the grain boundary since the (110) peak of the $\alpha-F e$ returns to its original position regardless of the presence of additives. The $\mathrm{Zr}_{\mathrm{r}}$ in the grain boundary retards the grain growth and controls the thickness of the boundary between the two phases. The grain size in the resulting nanostructure is reduced from (20-30) $\mathrm{nm}$ to $(10-20) \mathrm{nm}$.

Mössbauer spectroscopy was used for phase analysis. The ${ }^{57} \mathrm{Fe}$ spectra were measured on a constant acceleration spectrometer with a $10-15 \mathrm{mCi}$ source of ${ }^{57} \mathrm{Co}$ in a rhodium matrix. Powder samples were mixed with icing sugar to make a uniformly-dispersed absorber. Susceptibility measurements were made using a double coil coaxial detection system operating at $10 \mathrm{~Hz}-1 \mathrm{kHz}$ with a driving field of $(80-1000) \mathrm{A} / \mathrm{m}$.

\section{RESULTS}

\section{(i) Characterization of grain boundary phase}

In the $\mathrm{Sm}_{2} \mathrm{Fe}_{17} \mathrm{~N}_{3} / \mathrm{Fe}$ system with an average grain size of $\sim 20 \mathrm{~nm}, 10-15 \%$ of the material is found to lie in a grain boundary phase. This has been evidenced in Mössbauer spectra and in transmission electron microscope lattice images where it was seen to extend over a distance of order $1 \mathrm{~nm}$ [4]. There are four distinct iron sites in $\mathrm{Sm}_{2} \mathrm{Fe}_{17} \mathrm{~N}_{3} / \mathrm{Fe}(18 \mathrm{~h}, 18 \mathrm{f}, 9 \mathrm{~d}, 6 \mathrm{c})$ and a single $\alpha$-Fe site [5]. From analysis of room temperature Mössbauer spectra such as the one shown in Fig. 1, there are in addition three other sites $\left(B_{1}, B_{2}, B_{3}\right)$ that we associate with the grain boundary, an 'iron-like' $\mathrm{B}_{1}$ majority site with a hyperfine field $\left(\mathrm{B}_{\mathrm{hf}}\right)$ of $28 \mathrm{~T}$, a second site $\mathrm{B}_{2}$ in a $\mathrm{Sm}$-rich environment with $\mathrm{B}_{\mathrm{hf}} \sim$ $12 \mathrm{~T}$ and a minor third $\mathrm{B}_{3}$ site which is nonmagnetic at room temperature. The grain boundary is nitrogen-rich and its magnetization is $\mu_{0} \mathrm{M}_{\mathrm{s}} \sim 1.2 \mathrm{~T}$, less than that of $\mathrm{Sm}_{2} \mathrm{Fe}_{17} \mathrm{~N}_{3}$. By contrast, the grain boundary in $\mathrm{Nd}_{2} \mathrm{Fe}_{14} \mathrm{~B} / \mathrm{Fe}$ with a similar grain size accounts for only $4-5 \%$ of the total iron content. This suggests that the grain boundary phase in the $\mathrm{Sm}-\mathrm{Fe}-\mathrm{N}$ system of thickness $\mathrm{t} \sim 1-5 \mathrm{~nm}$ is largely a 


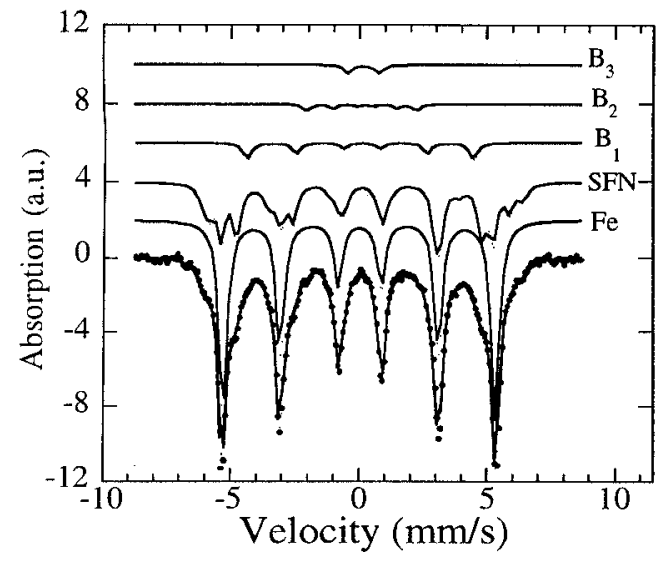

Fig. 1. Mössbauer spectra of $\mathrm{Sm}_{2} \mathrm{Fe}_{17} \mathrm{~N}_{3} / \alpha-\mathrm{Fe}(74 / 26)$ together with subspectra for $\alpha-\mathrm{Fe}, \mathrm{Sm}_{2} \mathrm{Fe}_{17} \mathrm{~N}_{3}$ and grain boundary phase $\left(\mathrm{B}_{1}, \mathrm{~B}_{2}, \mathrm{~B}_{3}\right)$.

decomposition product of the nitriding process $\left(330^{\circ} \mathrm{C}\right.$ for 45 hours) whereas the 'grain boundary' in the $\mathrm{Nd}-\mathrm{Fe}-\mathrm{B}$ system is really just the interface between $\mathrm{Nd}_{2} \mathrm{Fe}_{14} \mathrm{~B}$ and $\alpha-\mathrm{Fe}$. During the initial stages of decomposition of metastable $\mathrm{Sm}_{2} \mathrm{Fe}_{17} \mathrm{~N}_{3}$, Fe atoms which are assumed to be the faster diffusor move from the surface of the $\mathrm{Sm}_{2} \mathrm{Fe}_{17} \mathrm{~N}_{3}$ grains into the grain boundary which has a loose structure which can easily accomodate them leading to an increase in the grain boundary thickness. Fig. 2 shows a histogram of the relative proportions of iron in the two phases and the grain boundary in nanocomposites with different $\mathrm{Sm}_{2} \mathrm{Fe}_{17} \mathrm{~N}_{3} / \mathrm{Fe}$ ratios deduced from Mössbauer spectra (after a correction for the recoilless fractions).

Fig. 3 shows the room temperature Möss bauer spectrum for a typical $\mathrm{Nd}_{2} \mathrm{Fe}_{14} \mathrm{~B} / \alpha-\mathrm{Fe}$ nanocomposite. The fractions of $\mathrm{Nd}_{2} \mathrm{Fe}_{14} \mathrm{~B}, \mathrm{Fe}$ and grain boundary material in two different samples (a) $\mathrm{Nd}_{8} \mathrm{Fe}_{88.5} \mathrm{~B}_{3.5}$ and (b) $\mathrm{Nd}_{13} \mathrm{Fe}_{81.7} \mathrm{~B}_{5.3}$ deduced from Mössbauer spectra are given in table $I$. The grain boundary material is identified with a doublet near 0 $\mathrm{mm} / \mathrm{s}$. The results suggest that the grain boundary may again be associated with the rare-earth intermetallic.

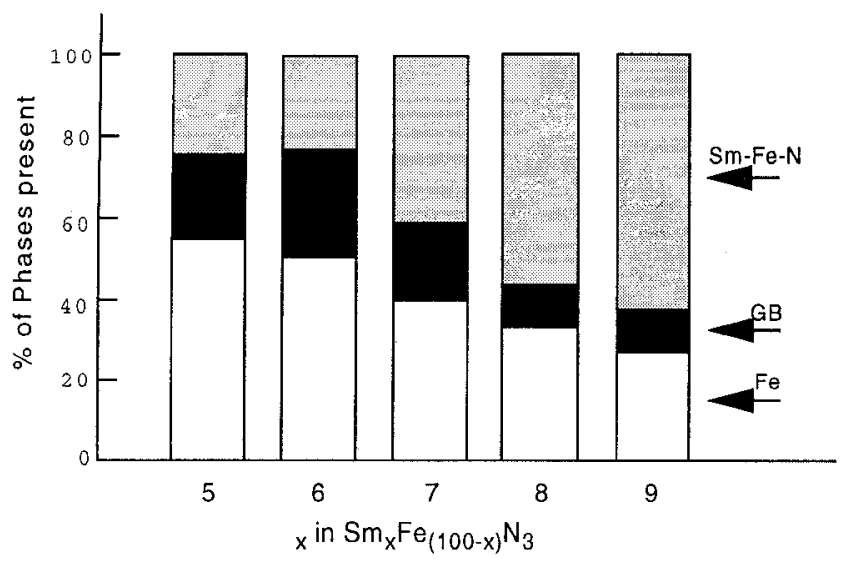

Fig. 2. Histogram showing the variation in the amount of grain boundary material with $\mathrm{Sm}$ content $\mathrm{x}$ in $\mathrm{Sm}_{\mathrm{X}} \mathrm{Fe}_{100-\mathrm{X}} \mathrm{N}$ two-phase nanocomposites of $\mathrm{Sm}_{2} \mathrm{Fe}_{17} \mathrm{~N}_{3} / \alpha-\mathrm{Fe}$.

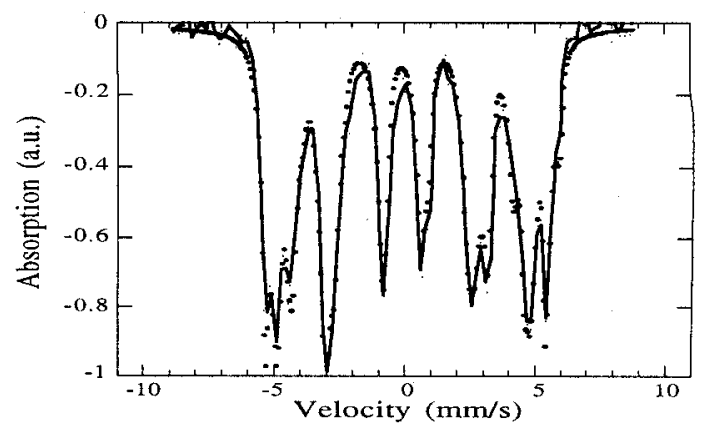

Fig. 3. Room temperature Mössbauer spectrum of a $\mathrm{Nd}_{2} \mathrm{Fe} 14 \mathrm{~B} / \alpha-\mathrm{Fe}$ nanocomposite with a composition $\mathrm{Nd}_{13} \mathrm{Fe}_{81.7} \mathrm{~B}_{5.3}$.

TABLE I

Fractions OF $\mathrm{Nd}_{2} \mathrm{Fe}_{14} \mathrm{~B}, \mathrm{Fe}$ And Grain Boundary Phases IN $\mathrm{Nd}_{2} \mathrm{Fe}_{14} \mathrm{~B} / \mathrm{Fe}$ NANOCOMPOSITES OF COMPOSITION (a) Nd8 $\mathrm{Fe}_{88.5} \mathrm{~B}_{3.5}$ AND (b) $\mathrm{Nd}_{13} \mathrm{Fe}_{81.7^{\mathrm{B}} \mathrm{B} .3}$

$\mathrm{Nd}_{2} \mathrm{Fe}_{14} \mathrm{~B}(\%) \quad \mathrm{Fe}(\%) \quad$ Grain Boundary $(\%)$

$\begin{array}{llll}\text { (a) } & 36 & 60 & 4 \\ \text { (b) } & 74 & 21 & 5\end{array}$

(ii) Susceptibility versus temperature measurements

Susceptibility of two samples 'A' and 'B' which have the same $\mathrm{Sm}: \mathrm{Fe}$ ratio (7:93), but in the case of ' $\mathrm{A}$ ' 2 at.\% $\mathrm{Zr}$ has been added to refine the grain structure has been measured. The susceptibility of the well-coupled sample 'A' $(10-20 \mathrm{~nm}$ grain size, showing a 'single phase' hysteresis loop, with $\mathrm{J}_{\mathbf{r}}$ $=1.06 \mathrm{~T}, \mathrm{H}_{\mathrm{C}}=3.15 \mathrm{kA} / \mathrm{cm}$ with $13 \%$ grain boundary material, $\mathrm{t} \sim 1 \mathrm{~nm}$ ) and the poorly coupled sample ' $\mathrm{B}$ ' $(20$ $30 \mathrm{~nm}$ grain size, showing a less square loop, with $15 \%$ grain boundary phase, $\mathrm{t} \sim 2 \mathrm{~nm}$ ) are compared in Fig. 4 . In both cases the high temperature peak appears below the Curie point of pure iron $\left(770^{\circ} \mathrm{C}\right)$. In the well-coupled sample the low temperature peak is sharp but is at a lower temperature than the Curie point of $\mathrm{Sm}_{2} \mathrm{Fe}_{17} \mathrm{~N}_{3}\left(470^{\circ} \mathrm{C}\right)$.

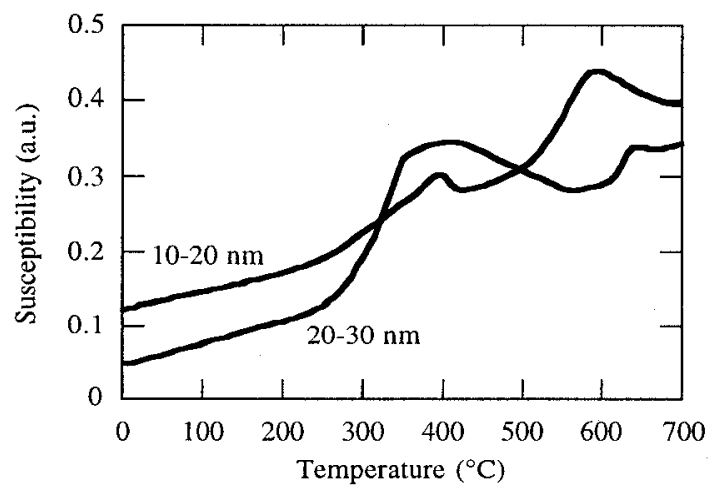

Fig. 4. AC susceptibility as a function of temperature for a) a well-coupled (10-20 nm grain size) and b) a poorly-coupled (20-30 nm grain size) nanocomposite of $\mathrm{Sm}_{2} \mathrm{Fe}_{17} \mathrm{~N}_{3} / \mathrm{Fe}$. 


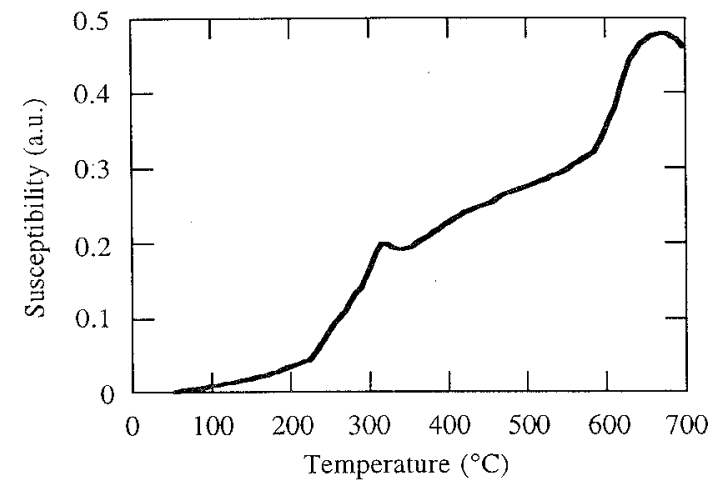

Fig. 5. Susceptibility versus temperature for a $\mathrm{Nd}_{2} \mathrm{Fe}_{14} \mathrm{~B} / \alpha-\mathrm{Fe}$

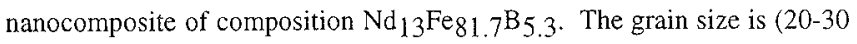
$\mathrm{nm})$.

When interpreting these data, it must be remembered that the $\mathrm{Sm}_{2} \mathrm{Fe}_{17} \mathrm{~N}_{3}$ has a tendency to decompose to $\mathrm{SmN}$ and nanocrystalline iron when heated above about $500^{\circ} \mathrm{C}$.

Susceptibility data for two-phase nanocomposites of $\mathrm{Nd}_{2} \mathrm{Fe}_{14} \mathrm{~B} / \mathrm{Fe}$ (20-30 nm grain size), where the amount of grain boundary phase is only 4 to $5 \%$ and neither phase decomposes over the temperature range used, are shown in Fig. 5. It is similar to that of the well-coupled $\mathrm{Sm}_{2} \mathrm{Fe}_{17} \mathrm{~N}_{3} / \mathrm{Fe}$ system.

\section{DISCUSSION}

In order to discuss the temperature-dependence of the susceptibility of our nanocomposite samples, we first note that the susceptibility of an assembly of completely uncoupled ferromagnetic particles would show two sharp peaks, at the Curie temperatures of the two constituent phases. As the particle size decreases towards the nanometer range, the peaks are expected to broaden and shift to lower temperature as finite size prevents the divergence of the correlation length at $\mathrm{Tc}$, and the absence of bonds at the surface weakens the average exchange coupling. Eventually, the susceptibility peak becomes very broad and shifts towards zero temperature as the particles become superparamagnetic.

The challenge is to understand the effect of interface coupling. If small particles are exchange coupled to the extent that the particles of the high-Tc phase interact with each other, either directly or via the other phase, the upper susceptibility peak will be sharp as there is a bulk phase transition, but the other peak will be broad. Wang and Mills [6] have developed a model for a two-component multilayer superlattice using Ginzberg-Landau theory, where the nearest-neighbour character of the Heisenberg exchange is represented by a very short coherence length, equal to the lattice spacing. As the thickness of the two components is decreased, the higher temperature peak remains sharp, but the lower-temperature peak is broader, corresponding to the turning on of signifcant magnetic order in the second component. This broadening continues as the thickness decreases, disappearing for a thickness of about two monolayers, at which point there remains one sharp peak at a temperature determined by a suitable average of the interlayer and intralayer exchange interactions. For exchange-coupled layers thicker than about ten lattice spacings, two well-defined peaks appear in the susceptibility. In general, decreasing the particle size or layer thickness increases the weighting of the interlayer or interparticle coupling since it is a surface effect, whereas the intralayer or intraparticle exchange scales with the volume.

We observe in Fig. 4 that the less-coupled 20-30 nm sample shows a fairly sharp transition at about $650^{\circ} \mathrm{C}$, but a very broad and intense anomaly around $400^{\circ} \mathrm{C}$. This may be understood if most of the iron particles are superparamagnetic, which is likely for particles of this size in this temperature range [7]. The blocking temperature of much of the iron is supposed to be about $400^{\circ} \mathrm{C}$. In the strongly-coupled sample, on the other hand, the interparticle coupling precludes the possibility of superparamagnetic behaviour. The lower peak in this case is entirely due to the onset of magnetic odrer in the hard $\mathrm{Sm}-\mathrm{Fe}-\mathrm{N}$ phase. The strongly-coupled particles in the $\mathrm{Nd}_{2} \mathrm{Fe}_{14} \mathrm{~B} / \mathrm{Fe}$ nanocomposites (Fig. 5) exhibit a similar structure in susceptibility. Generally, the upper peaks are at a temperature which is unexpectedly lower than the Curie point of $\alpha-\mathrm{Fe}$. The fractional reduction due to the Curie temperature due to small particle size should be of order $3 \mathrm{a} / 2 \mathrm{r}$ where $\mathrm{a}$ is the interatomic spacing and $\mathrm{r}$ is the particle radius. For iron particles $10 \mathrm{~nm}$ in diameter, this is approximately 0.1 .

\section{CONCLUSIONS}

A grain boundary region constituting $\approx 15$ volume $\%$ of the two-phase nanocomposite in the case of $\mathrm{Sm}_{2} \mathrm{Fe}_{17} \mathrm{~N}_{3} / \mathrm{Fe}$ and $\Rightarrow 5$ volume $\%$ in the case of $\mathrm{Nd}_{2} \mathrm{Fe}_{14} \mathrm{~B} / \mathrm{Fe}$ has been identified and characterized using Mössbauer spectroscopy. This region controls the degree of coupling between hard and soft magnetic phases. The susceptibility of wellcoupled two-phase nanocomposites shows a two-peak structure in qualitative agreement with the mean-field model of Wang and Mills.

\section{REFERENCES}

[1] "Rare Earth Iron Permanent Magnets", J. M. D. Coey (ed), Oxford University Press (1996).

[2] T. Schrefl, R. Fischer, J. Fidler and H. Kronmüller, "Two- and threedimensional calculation of remanence enhancement of rare-earth based composite magnets“, J. Appl. Phys. vol. 76, pp.7053-7058, November 1994.

[3] T. Schrefl, H. Roitner and J. Fidler, "Dynamic micromagnetics of nanocomposite $\mathrm{NdFeB}$-magnets" J. Appl. Phys. (1997) in press.

[4] K. O'Donnell and J. M. D. Coey, J. Appl. Phys. (1997) in press. [5] Bo-Ping Hu, Hong-Shuo Li, Hong Sun and J. M. D. Coey, "A ${ }^{57} \mathrm{Fe}$ Mössbauer study of a new series of rare-earth iron nitrides: $\mathrm{R}_{2} \mathrm{Fe}_{17} \mathrm{~N}_{3}-\delta$ ", J. Phys.: Condens. Mater vol. 3, pp. 3983-3995, June 1991.

[6] R. W. Wang and D. L. Mills, "Onset of long-range order in superlattices: Mean-field theory", Phys. Rev. B. vol. 46, PP. 1168111687, November 1992.

[7] "Theory of Ferromagnetism", A. Aharoni, Oxford University Press (1996) 